\title{
Ventricular assist device support after biventricular excision: Assistance or alternative?
}

\author{
Jason J. Han, MD, and Pavan Atluri, MD
}

\footnotetext{
From the Division of Cardiovascular Surgery, Department of Surgery, University of Pennsylvania, Philadelphia, $\mathrm{Pa}$.

Disclosures: Authors have nothing to disclose with regard to commercial support.

Received for publication Nov 28, 2017; accepted for publication Dec 4, 2017; available ahead of print Jan 5, 2018 Address for reprints: Pavan Atluri, MD, Division of Cardiovascular Surgery, Hospital of the University of Pennsylvania, 3400 Spruce St, 6 Silverstein Pavilion, Philadelphia, PA 19104 (E-mail: Pavan.Atluri@uphs.upenn. edu).

J Thorac Cardiovasc Surg 2018;155:1635-6

$0022-5223 / \$ 36.00$

Copyright (C) 2017 by The American Association for Thoracic Surgery

https://doi.org/10.1016/j.jtcvs.2017.12.007
}

Rapidly expanding use of mechanical circulatory support platforms for resuscitative indications has led to remarkable recovery and survival among patients whose conditions would have been invariably deemed fatal in the past. Postinfarction cardiac arrest refractory to resuscitation and revascularization compose a large percentage of these cases. $^{1,2}$ Numerous bridging strategies with various combinations of ventricular assist devices (VADs) and extracorporeal membrane oxygenation (ECMO) have been demonstrated, although high rates of complications require exceptionally careful patient selection, surgical planning, and perioperative management. ${ }^{3-6}$ Technical challenges still remain in the creation of such increasingly hybrid physiology, most importantly in our abilities to restore adequate flow, to achieve hemostasis, and to preserve the anatomy for future transplant or other, more definitive therapies.

The novel technique reported by Carrozzini and colleagues $^{7}$ in this issue of the Journal of paracorporeal biventricular VAD implantation after biventricular excision is precisely at the frontier of this burgeoning realm. ${ }^{6}$ In this report, the patient was precluded from heart transplantation or conventional VAD implantation at the time of hemodynamic compromise because of prohibitively high thromboembolic risk from extensive intraventricular thrombosis. Although the patient was promptly placed on peripheral venoarterial ECMO and confirmed to have intact neurologic status, he had worsening lactic acidosis and renal and pulmonary dysfunction in the absence of adequate left ventricular unloading. His prognosis, if limited to standard surgical approaches, would have been fatal. Given such circumstances, the approach of Carrozzini and colleagues ${ }^{7}$ to convert from ECMO to paracorporeal biventricular VAD with biventricular excision demonstrates ingenuity and versatility. Doing so simultaneously accomplished 2 essential goals that prolonged ECMO therapy in this case could not have done: (1) near-complete elimination of thromboembolic burden and (2) recovery from shock patients.

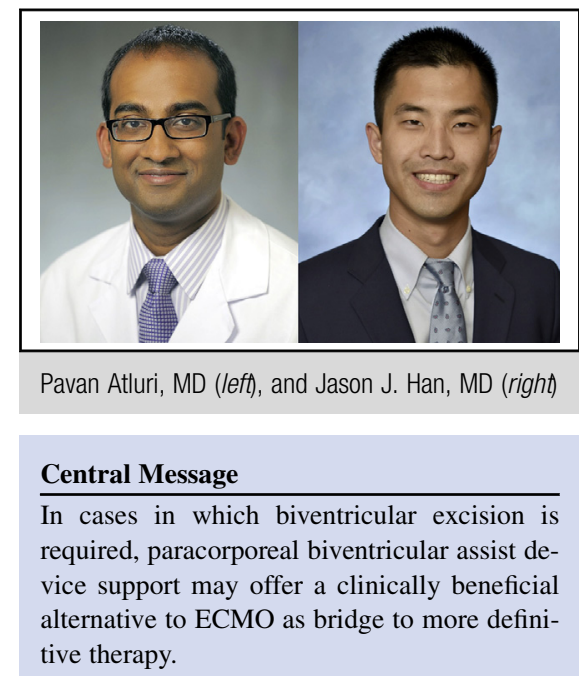

See Article page 1632 .

and end-organ failure in preparation for bridging to more durable therapy, such as transplant or a total artificial heart. Whereas traditional ECMO therapy often has a finite window, after which point end-organ compromise is inevitable, temporary biventricular support has been shown to be stable for weeks. ${ }^{8,9}$

Several notable technical insights should be gleaned from this report and could guide future endeavors. First, direct left atrial cannulation not is only surgically feasible through careful preservation of the fibrous skeleton and the creation of a rigid cuff but also permits excellent flow and reasonable hemostasis. Even outside this specific context, this technique may offer a solution for patients, such as those with hypertrophic cardiomyopathy, for whom fear of suction events prohibits ventricular cannulation, or those with postinfarction ventricular septal defect. Second, although the patient died after the operation of an ischemic stroke, which Carrozzini and colleagues ${ }^{7}$ presume to have come from an upstream, aortic source, the use of oxygenators in the circuit theoretically mitigated the risk of systemic thromboembolism despite high clot burden in the cardiac chambers and pulmonary vasculature. This report demonstrates a clear example of the sort of ingenuity and out-of-the-box thinking that we as surgeons ought to invoke in applying mechanical circulatory support to our critically ill 
Many questions regarding the patient's postoperative course remain after reading this report, and the answers will help determine the technique's true feasibility as a bridge platform. In addition to VAD flow, longer observations of end-organ function and rates of device-related complications will need to be analyzed. In our experience, surgical innovation in this setting is only as meaningful as its ability to bridge to durable platforms.

As the capability of mechanical circulatory support devices and our abilities to manage them effectively continue to improve, we will simultaneously experience the unlimited potential and the unforeseen challenges of these increasingly complex, bionic approaches. Carrozzini and colleagues $^{7}$ are to be commended for their innovative work, which demonstrates a technical foundation to help patients who are otherwise without options or hope.

\section{References}

1. Stub D, Bernard S, Pellegrino V, Smith K, Walker T, Sheldrake J, et al. Refractory cardiac arrest treated with mechanical CPR, hypothermia, ECMO and early reperfusion (the CHEER trial). Resuscitation. 2015;86:88-94.
2. Stub D, Bernard S, Duffy SJ, Kaye DM. Post cardiac arrest syndrome: a review of therapeutic strategies. Circulation. 2011;123:1428-35.

3. Tarzia V, Bortolussi G, Bianco R, Buratto E, Bejko J, Carrozzini M, et al. Extracorporeal life support in cardiogenic shock: impact of acute versus chronic etiology on outcome. J Thorac Cardiovasc Surg. 2015;150:333-40.

4. Han JJ, Chung J, Chen CW, Gaffey AC, Sotolongo A, Justice C, et al. Different clinical course and complications in Interagency Registry for Mechanically Assisted Circulatory Support 1 patients managed with or without extracorporeal membrane oxygenation. ASAIO J. September 21, 2017 [Epub ahead of print].

5. Fiser WP, Yetman AT, Gunselman RJ, Fasules JW, Baker LL, Chipman CW, et al. Pediatric arteriovenous extracorporeal membrane oxygenation (ECMO) as a bridge to cardiac transplantation. J Heart Lung Transplant. 2003;22:770-7.

6. Hirata Y, Charette K, Mosca RS, Quaegebeur JM, Chen JM. Pediatric application of the Thoratec CentriMag BiVAD as a bridge to heart transplantation. J Thorac Cardiovasc Surg. 2008;136:1386-7.

7. Carrozzini M, Toto F, Gerosa G, Bottio T. Irreversible cardiac failure with intraventricular thrombosis: a novel technique of paracorporeal biventricular assist device implantation with ventricles excision. J Thorac Cardiovasc Surg. 2018;155:1632-4.

8. Cleveland JC Jr, Naftel DC, Reece TB, Murray M, Antaki J, Pagani FD, et al. Survival after biventricular assist device implantation: an analysis of the Interagency Registry for Mechanically Assisted Circulatory Support database. J Heart Lung Transplant. 2011;30:862-9.

9. Pages ON, Aubert S, Combes A, Luyt CE, Pavie A, Léger P, et al. Paracorporeal pulsatile biventricular assist device versus extracorporeal membrane oxygenationextracorporeal life support in adult fulminant myocarditis. J Thorac Cardiovasc Surg. 2009; 137:194-7. 